Available online at http://journal.uad.ac.id/index.php/Konvergensi

Jurnal Ilmiah Matematika 7 (2), 2020, 65-72

\title{
Implementasi Fuzzy Neural Network untuk Peramalan Penjualan Sepeda Motor
}

(Fuzzy Neural Network Implementation for Motorcycle Sales Forecasting)

\author{
Diska Yulia Maisarah ${ }^{1}$ *, Sugiyarto ${ }^{2}$ \\ Universitas Ahmad Dahlan, Indonesia \\ E-mail: diska1500015017@webmail.uad.ac.id \\ * Corresponding Author
}

\begin{tabular}{|c|c|}
\hline ARTICLE INFO & ABSTRACT \\
\hline \multirow[t]{3}{*}{$\begin{array}{l}\text { Kata Kunci } \\
\text { Logika Fuzzy } \\
\text { Jaringan Syaraf Tiruan Fuzzy } \\
\text { Peramalan } \\
\text { Multi Layer Perceptron } \\
\text { Keywords } \\
\text { Fuzzy Logic } \\
\text { Fuzzy Neural Network } \\
\text { Forecasting } \\
\text { Multi Layer Perceptron }\end{array}$} & $\begin{array}{l}\text { Penelitian ini membahas tentang implementasi Fuzzy Neural Network untuk } \\
\text { peramalan penjualan sepeda motor di Cahaya Sakti Motor. Fuzzy Neural } \\
\text { Network merupakan salah satu system hybrid yang menggabungkan dua } \\
\text { metode yaitu logika fuzzy dan dan jaringan syaraf tiruan. Metode Fuzzy Neural } \\
\text { network yang digunakan dalam penelitian ini adalah kombinasi logika fuzzy } \\
\text { dengan pendekatan Multi Layer Perceptron. Penelitian ini bertujuan } \\
\text { mengetahui jumlah penjualan sepeda motor di tahun } 2019 \text { berdasarkan data } \\
\text { penjualan Januari } 2014 \text { hingga Desember } 2018 \text {. Berdasarkan hasil penelitian, } \\
\text { model Fuzzy Neural Network ini cocok digunakan untuk peramalan penjualan } \\
\text { sepda motor, karena nilai MSE yang diperoleh sangat kecil yaitu } 9.9924 \mathrm{e}-06 \\
\text { untuk data training dan } 0.0560 \text { untuk data testing. Adapun hasil peramalan } \\
\text { penjualan sepeda motor tahun } 2019 \text { di Cahaya Sakti Motor yaitu sebanyak } 153 \\
\text { unit pada bulan Januari, } 133 \text { unit pada bulan Februari, } 114 \text { unit pada bulan } \\
\text { Maret, } 116 \text { unit pada bulan April, } 125 \text { unit pada bulan Mei, } 157 \text { unit pada bulan } \\
\text { Juni, } 120 \text { unit pada bulan Juli, } 114 \text { unit pada bulan Agustus, } 122 \text { unit pada } \\
\text { bulan September, } 125 \text { unit pada bulan Oktober, } 160 \text { unit pada bulan November, } \\
\text { dan } 115 \text { unit pada bulan Desember. }\end{array}$ \\
\hline & $\begin{array}{l}\text { This study discusses the implementation of the Fuzzy Neural Network for } \\
\text { forecasting motorcycle sales at Cahaya Sakti Motor. Fuzzy Neural Network is } \\
\text { a hybrid system that combines two methods, namely fuzzy logic and artificial } \\
\text { neural networks. Fuzzy Neural network method used in this research is a } \\
\text { combination of fuzzy logic with the Multi Layer Perceptron approach. This } \\
\text { study aims to determine the number of motorcycle sales in } 2019 \text { based on sales } \\
\text { data from January } 2014 \text { to December } 2018 \text {. Based on the research results, the } \\
\text { Fuzzy Neural Network model is suitable for forecasting motorcycle sales, } \\
\text { because the MSE value obtained is very small, namely } 9.9924 \mathrm{e}-06 \text { for training } \\
\text { data and } 0.0560 \text { for testing data. The results of forecasting } 2019 \text { motorcycle } \\
\text { sales at Cahaya Sakti Motor are } 153 \text { units in January, } 133 \text { units in February, } \\
114 \text { units in March, } 116 \text { units in April, } 125 \text { units in May, } 157 \text { units in June, } 120 \\
\text { units in July, } 114 \text { units in August, } 122 \text { units in September, } 125 \text { units in October, } \\
160 \text { units in November, and } 115 \text { units in December. } \\
\text { This is an open access article under the CC-BY-SA license. }\end{array}$ \\
\hline & (c) $\underset{\mathrm{BY}}{\mathrm{i}}$ (?) \\
\hline
\end{tabular}




\section{PENDAHULUAN}

Pada era globalisasi, system computer berperan penting dalam berbagai kegiatan manusia, baik pada bidang kesehatan, ekonomi, perusahaan, maupun dalam lingkungan masyarakat umum. Salah satu aplikasi computer yang sering digunakan untuk menyelesaikan masalah sehari - hari adalah jaringan syaraf tiruan.

Jaringan syaraf tiruan adalah sebuah kecerdasan buatan seperti kinerja otak manusia dan mencoba untuk mensimulasikan proses pembelajaran pada otak manusia tersebut [1]. Salah satu aplikasi jaringan syaraf tiruan yang banyak digunakan adalah dalam hal peramalan.

Peramalan adalah suatu proses untuk memperkirakan kebutuhan dimasa datang yang meliputi kebutuhan dalam ukuran kuantitas, kualitas, waktu, dan lokasi yang dibutuhkan dalam rangka memenuhi permintaan barang atau jasa berdasarkan data histori yang ada [2]. Pada realitanya, peramalan dilakukan terhadap sesuatu yang belum atau tidak pasti terjadi. Logika fuzzy mempunyai peran yang sangat penting untuk menghadapi kondisi yang tidak pasti[3][4]. Logika fuzzy merupakan suatu kecerdasan buatan yang dapat memberikan toleransi terhadap data yang tidak tepat.

Konsep logika fuzzy lebih sederhana, mudah dimengerti serta memiliki toleransi terhadap data yang tidak tepat, namun tidak mampu memperoleh aturan secara otomatis[5][6][7]. Adapun jaringan syaraf tiruan, mampu mengolah aturan fuzzy dengan proses pembelajaran yang dimilikinya. Akan tetapi, proses pembelajaran ini relative lambat dan analisis jaringan yang terlatih sulit untuk jaringan yang cukup besar.

Berdasarkan kekurangan dan kelebihan yang dimiliki oleh logika fuzzy dan jaringan syaraf tiruan, maka dalam penelitian ini akan menggabungkan kedua metode tersebut, yang dikenal dengan system hybrid. Adapun system hybrid yang digunakan dalam penelitian ini yaitu Fuzzy Neural Network. Metode Fuzzy Neural Network yang digunakan adalah kombinasi logika fuzzy dan jaringan syaraf tiruan yang akan digunakan untuk peramalan penjualan sepeda motor.

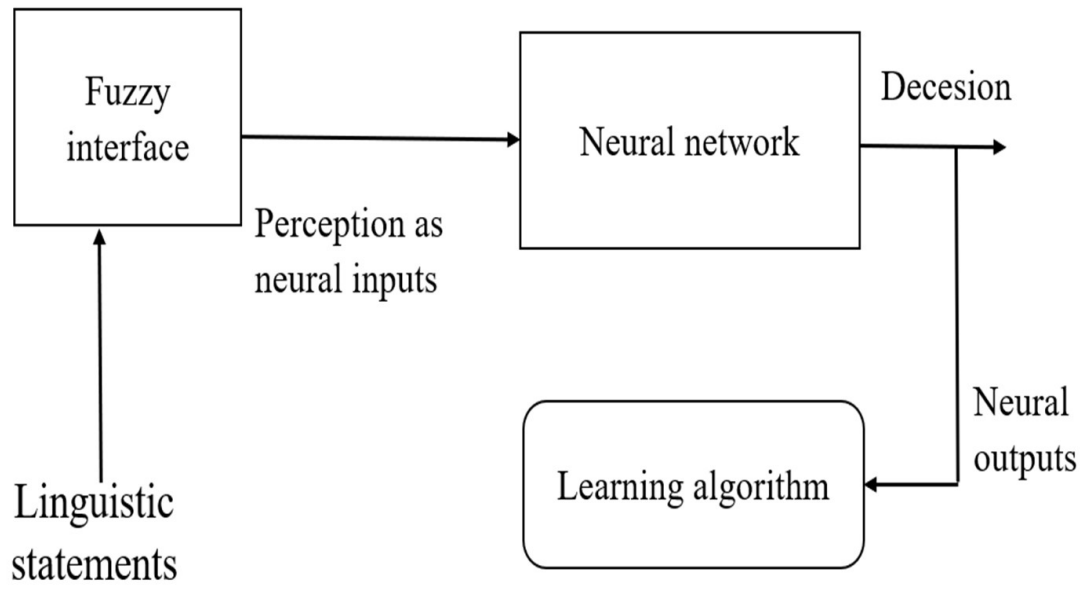

Fig. 1. Arsitektur Fuzzy Neural Network

\section{METODE}

\subsection{Objek penelitian}

Objek yang digunakan dalam penelitian ini adalah data bulanan jumlah penjualan sepeda motor Honda dari Januai 2014 hingga Desember 2018 yang diperoleh dari dealer Cahaya Sakti Motor. Data penjualan sepeda motor dapat dilihat pada Tabel.1. 
Jurnal Ilmiah Matematika, 7 (2), 2020 - 67

Diska Yulia Maisarah, Sugiyarto

Table 1. Data Penjualan Sepeda MotorJanuari 2014 sampai dengan Desember 2018

\begin{tabular}{lccccc}
\hline Bulan & $\begin{array}{c}\mathbf{2 0 1 4} \\
\text { (Unit) }\end{array}$ & $\begin{array}{c}\mathbf{2 0 1 5} \\
\text { (Unit) }\end{array}$ & $\begin{array}{c}\mathbf{2 0 1 6} \\
\text { (Unit) }\end{array}$ & $\begin{array}{c}\mathbf{2 0 1 7} \\
\text { (Unit) }\end{array}$ & $\begin{array}{c}\mathbf{2 0 1 8} \\
\text { (Unit) }\end{array}$ \\
\hline Jan & 172 & 124 & 159 & 107 & 118 \\
Feb & 116 & 100 & 116 & 79 & 97 \\
Mar & 124 & 96 & 124 & 73 & 85 \\
Apr & 113 & 85 & 96 & 89 & 72 \\
Mey & 99 & 109 & 102 & 66 & 81 \\
Jun & 123 & 103 & 145 & 77 & 63 \\
Jul & 163 & 130 & 108 & 109 & 100 \\
Aug & 121 & 117 & 125 & 108 & 131 \\
Sep & 277 & 122 & 109 & 135 & 125 \\
Okt & 124 & 124 & 111 & 113 & 100 \\
Nov & 130 & 115 & 97 & 101 & 98 \\
Dec & 97 & 115 & 127 & 124 & 78 \\
\hline
\end{tabular}

\subsection{Logika fuzzy}

Logika fuzzy pertama kali diperkenalkan oleh Lotfi A. Zadeh pada tahun 1965 sebagai sarana untuk memanupulasi data yang tidak tepat dan bersifat kabur. Logika fuzzy adalah suatu cara yang tepat untuk memetakan suatu ruang input ke dalam suatu ruang output.

Suatu himpunan fuzzy $\tilde{A}$, dalam X didefenisikan sebagai himpunan pasangan berurut,

$$
\tilde{\mathrm{A}}=\left\{\left(x, \mu_{\tilde{\mathrm{A}}}(x)\right) \mid x \in X\right\}(1)
$$

dengan $\mu_{\tilde{\AA}}(x)$ adalah derajat keanggotaan $x$ dalam $\tilde{A}$ yang memetakan $X$ ke ruang keanggotaan $M$ yang terletak pada rentang $[0,1][8]$.

\subsection{Jaringan syaraf tiruan}

Jarigan syaraf tiruan diperkenalkan oleh McCulloh dan Pits pada tahun 1943, Hebb pada tahun 1949 memperkenalkan sebuah Teknik pelatihan jaringan syaraf tiruan yang dinamakan Hebbian Rule. Pada tahun 1961 Rosenbaltt memperkenalkan jaringan syaraf satu lapis yang diberi nama perseptron dan digunakan untuk pengenalan pola optis.

Jaringan syaraf tiruan adalah salah satu representasi dari otak manusia yang mencoba untuk mensimulasikan proses pembelajaran pada otak manusia tersebut [9]. Penelitian ini menggunakan arsitektur jaringan syaraf dengan banyak lapisan, yang memiliki satu atau lebih lapisan yang terletak diantara lapisan input dan output (memiliki satu atau lebih lapisan tersembunyi). Jaringan ini dapat menyelesaikan permasalahan yang lebih sulit daripada lapisan dengan lapisan tunggal, tentu saja dengan pembelajaran yang lebih rumit. Jaringan syaraf dengan banyak lapisan dapat dilihat pada Gambar. 2.

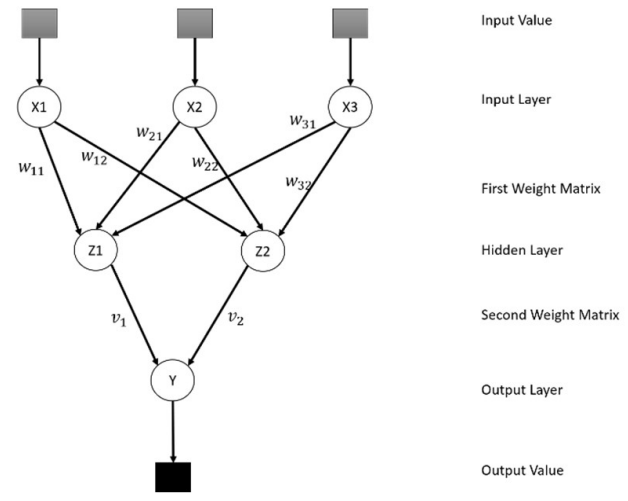

Fig. 2. Jaringan Syaraf dengan Banyak Lapisan 
Adapun fungsi aktivasi yang digunakan adalah sigmoid biner. Fungsi sigmoid biner adalah fungsi aktivasi yang digunakan untuk jaringan yang yang dilatih dengan menggunakan metode backpropagation. Fungsi ini memiliki nilai pada range 0 sampai 1. Oleh karena itu fungsi ini sering digunakan untuk jaringan syaraf yang membutuhkan nilai output yang terletak pada interval 0 sampai 1. Namun, fungsi ini juga bias digunakan oleh jaringan syaraf yang nilai outputnya 0 atau 1 . Fungsi aktivasi sigmoid biner dapat dilihat pada Gambar. 3 .

$$
y=\frac{1}{1+e^{\sigma x}}
$$

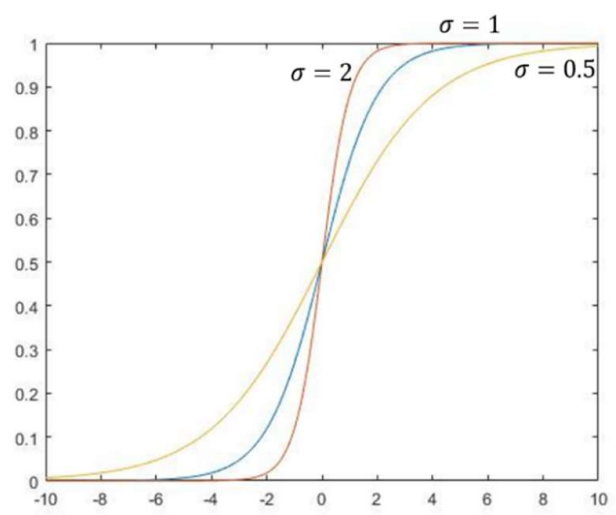

Fig. 3. Fungsi Aktivasi Sigmoid Biner

\section{$1.4 \quad$ Fuzzy neural network}

Fuzzy neural network merupakan salah satu system hybrid yang menggabungkan dua metode yaitu logika fuzzy dan jaringan syaraf tiruan. Adapun langkah - langkah dalam fuzzy neural network adalah sebagai berikut :

1. Menentukan himpunan semesta masing - masing variabel

2. Membentuk sebuah himpunan fuzzy masing - masing variabel

3. Menentukan fungsi keanggotaan himpunan fuzzy. Penelitian ini menggunakan fungsi keanggotaan gauss sebagai berikut :

$$
\mathrm{G}\left(x_{i} ; \sigma ; \mathrm{c}\right)=e^{\frac{-\left(x_{i}-c\right)^{2}}{2 \sigma^{2}}}
$$

Dengan $x_{i}$ adalah data input ke-i, parameter $\sigma$ merupakan lebar kurva, dan parameter c merupakan nilai domain pada pusat kurva. Fungsi keanggotaan gauss dapat dilihat pada Gambar. 4.

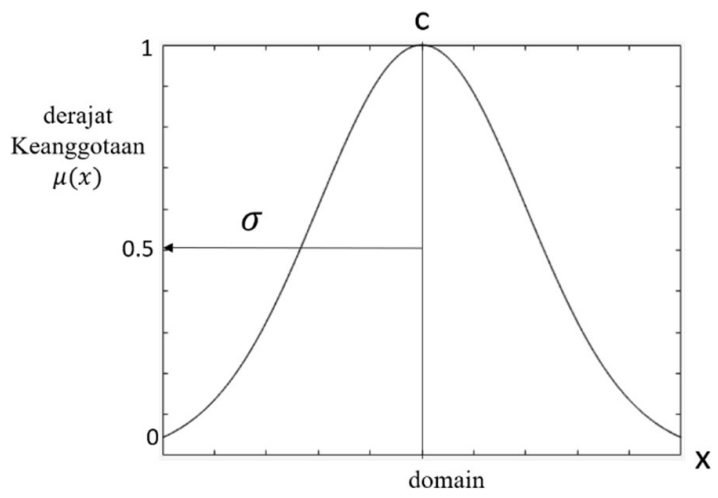

Fig. 4. Grafik Fungsi Keanggotaan Gaussian 
4. Menentukan derajat keanggotaan himpunan fuzzy berdasarkan fungsi keanggotaan untuk masing maing variabel

5. Membentuk jaringan syaraf tiruan :

a. Defenisikan matriks input

b. Inisialisasi jumlah node pada hidden layer

c. Inisialisasi nilai ambang sebagai kondisi berhenti serta menentukan bobot dan bias dari input layer ke hidden layer dan dari hidden layer ke output layer dengan nilai random

d. Ulangi langkah - langkah berikut selama kondisi berhenti belum terpenuhi:

Feedforward

- Setiap unit input menerima sinyal input dan meneruskan sinyal tersebut pada hidden layer

- Fungsi aktivasi yang digunakan pada hidden layer adalah sigmoid biner

$$
Z_{j}=\frac{1}{1+e^{-Z_{\text {net }}}}
$$

dengan :

$$
Z_{n e t_{j}}=\sum_{i=1}^{p} w_{i j} * \mathrm{G}\left(x_{i} ; \sigma ; \mathrm{c}\right)+b_{j}(5)
$$

- Hasil $Z_{j}$ digunakan untuk menghitung keluaran dari output layer $Y_{k}$

$$
Y_{n e t_{k}}=\sum_{j=1}^{q} v_{j k} * Z_{j}+b_{k}(6)
$$

dengan :

$$
Y_{k}=\frac{1}{1+e^{-Y} \text { net }_{k}}
$$

- Hasil $Y_{k}$ dibandingkan dengan nilai target yang diinginkan. Selisih nilai target dengan $Y_{k}$ adalah nilai error

Backpropagation

- Hitung $\delta$ output layer berdasarkan error di $Y_{k}$

$$
\delta_{k}=\left(1-Y_{k}^{2}\right) * \text { Error }(8)
$$

- Hitung perubahan bobot $v_{j k}$ dengan learning rate $\eta$

$$
\Delta v_{j k}=\eta * \delta_{k} * Z_{j}(9)
$$

- Hitung perubahan bias $b_{k}$

$$
\Delta b_{k}=\eta * \delta_{k}
$$

- Nilai error yang diperoleh dikembalikan lagi ke lapisan sebelumnya (hidden layer). Neuron pada lapisan tersebut akan memperbaiki nilai bobot dan biasnya.

$$
\delta_{k}=\left(1-Z_{j}^{2}\right) * v_{j k} * \delta_{k}(11)
$$

- Setelah neuron - neuron mendapatkan nilai yang sesuai dengan konstribusinya pada error, maka bobot dan bias jaringan akan diperbaiki agar error dapat diperkecil

$$
\begin{gathered}
v_{j k}=v_{j k}+\Delta v_{j k} \\
b_{k}=b_{k}+\Delta b_{k}
\end{gathered}
$$


Jurnal Ilmiah Matematika, 7 (2), 2020 - 70

Diska Yulia Maisarah, Sugiyarto

$$
\begin{aligned}
& w_{i j}=w_{i j}+\Delta w_{i j} \\
& b_{j}=b_{j}+\Delta b_{j}
\end{aligned}
$$

- Bobot dan bias hasil perbaikan dapat digunakan kembali untuk mengetahui error yang dihasilkan cukup kecil

Keterangan :

$Z_{j}=$ lapisan tersembunyi ke-j, dengan $\mathrm{j}=1: \mathrm{q}$

$w_{i j}=$ bobot yang menghubungkan neuron pada input ke-I menuju neuron ke-j pada lapisan

tersembunyi

$x_{i}=$ neuron ke-i pada lapisan input, dengan $\mathrm{I}=1: \mathrm{p}$

$b_{j}=$ bias neuron ke-j pada lapisan tersembunyi

$v_{j k}=$ bobot yang menghubungkan neuron ke-j pada lapisan tersembunyi menuju neuron ke-k pada

lapisan output

$b_{k}=$ bias neuron ke-k pada lapisan output

$Y_{k}=$ neuron ke-k pada lapisan output, dengan $\mathrm{k}=1: \mathrm{r}$

\section{HASIL DAN PEMBAHASAN}

Peramalan penjualan sepeda motor dilakukan dengan menggunakan metode fuzzy neural network, yaitu kombinasi logika fuzzy dengan pendekatan multi layer perceptron. Langkah awal yang dilakukan adalah dengan mengubah data penjualan sepeda motor yang bernilai crisp menjadi bilangan fuzzy. Hal ini dilakukan melalui proses fuzzifikasi menggunakan fungsi keanggotaan gaussian. Hasil fuzzifikasi dapat dilihat pada Tabel.2.

Table 2. Hasil Fuzzifikasi Data penjualan Sepeda Motor

\begin{tabular}{cccccc}
\hline Bulan & $\begin{array}{c}\mathbf{2 0 1 4} \\
\text { (Unit) }\end{array}$ & $\begin{array}{c}\mathbf{2 0 1 5} \\
\text { (Unit) }\end{array}$ & $\begin{array}{c}\mathbf{2 0 1 6} \\
\text { (Unit) }\end{array}$ & $\begin{array}{c}\mathbf{2 0 1 7} \\
\text { (Unit) }\end{array}$ & $\begin{array}{c}\mathbf{2 0 1 8} \\
\text { (Unit) }\end{array}$ \\
\hline Jan & 0.9862 & 0.7642 & 0.6065 & 0.9824 & 0.8263 \\
Feb & 0.7326 & 0.9460 & 0.9355 & 0.8235 & 1.0000 \\
Mar & 0.7827 & 0.8776 & 0.9938 & 0.7278 & 0.9396 \\
Apr & 0.7132 & 0.6065 & 0.6065 & 0.9460 & 0.7631 \\
Mey & 0.6200 & 0.9978 & 0.7206 & 0.6065 & 0.8952 \\
Jun & 0.7766 & 0.9802 & 0.8570 & 0.7930 & 0.6065 \\
Jul & 0.9651 & 0.6065 & 0.8256 & 0.9701 & 0.9961 \\
Aug & 0.7642 & 0.9147 & 0.9969 & 0.9766 & 0.6065 \\
Sep & 0.6065 & 0.8125 & 0.8416 & 0.6065 & 0.7124 \\
Okt & 0.7827 & 0.7642 & 0.8718 & 0.9365 & 0.9961 \\
Nov & 0.8183 & 0.9460 & 0.6258 & 0.9999 & 0.9996 \\
Dec & 0.6065 & 0.9460 & 0.9999 & 0.7930 & 0.8554 \\
\hline
\end{tabular}

Langkah selanjutnya adalah membangun jaringan syaraf tiruan. Hal yang harus dakukan adalah menentukan bobot awal jaringan secara random dan menentukan jumlah neuron terbaik pada lapisan tersembunyi berdasarkan nilai akurasi tertinggi dengan cara trial dan error. Berikut ini adalah langkah langkah dalam menentukan bobot awal jaringan dan jumlah neuron pada lapisan tersembunyi. 
Jurnal Ilmiah Matematika, 7 (2), 2020 - 71

Diska Yulia Maisarah, Sugiyarto

Adapun hasil variasi jumlah neuron lapisan tersembunyi dengan cara trial dan error dapat dilihat pada Tabel.3.

Table 3. Hasil Variasi Jumlah Neuron Pada Lapisan Tersembunyi.

\begin{tabular}{ccccc}
\hline $\begin{array}{c}\text { Learning } \\
\text { Rate }\end{array}$ & $\begin{array}{c}\text { Jumlah } \\
\text { Neuron }\end{array}$ & Epoch & $\begin{array}{c}\text { MSE } \\
\text { Training }\end{array}$ & $\begin{array}{c}\text { MSE } \\
\text { Testing }\end{array}$ \\
\hline 0.5 & 10 & 5000 & $5.0870 \mathrm{e}-05$ & 0.0429 \\
& 20 & 5000 & $1.5964 \mathrm{e}-05$ & 0.0967 \\
& 30 & 5000 & $1.5681 \mathrm{e}-05$ & 0.0720 \\
& 40 & 5000 & $1.3070 \mathrm{e}-05$ & 0.0670 \\
0.1 & 50 & 5000 & $9.9992 \mathrm{e}-06$ & 0.0575 \\
& 10 & 5000 & 0.0018 & 0.0307 \\
& 20 & 5000 & $1.4910 \mathrm{e}-05$ & 0.0744 \\
& 30 & 5000 & $1.8258 \mathrm{e}-05$ & 0.0600 \\
0.01 & 40 & 5000 & $1.4236 \mathrm{e}-05$ & 0.0403 \\
& 50 & 5000 & $9.9962 \mathrm{e}-06$ & 0.0494 \\
& 10 & 5000 & $8.8991 \mathrm{e}-05$ & 0.0873 \\
& 20 & 5000 & $2.2897 \mathrm{e}-05$ & 0.0368 \\
& 30 & 5000 & $1.3030 \mathrm{e}-05$ & 0.0481 \\
& 40 & 5000 & $1.6418 \mathrm{e}-05$ & 0.0782 \\
& 50 & 5000 & $9.9924 \mathrm{e}-06$ & 0.0560 \\
\hline
\end{tabular}

Berdasarkan Tabel.3 dapat dilihat bahwa nilai MSE hasil training terendah adalah 9.9924e-06 dengan menggunakan 50 neuron pada lapisan tersembunyi dan nilai learning rate adalah sebesar 0.01 yang akan digunakan untuk proses pembelajaran sehingga bmenghailkan output berupa hasil peramalan penjualan sepeda motor. Dengan demikian, pada penelitian ini akan digunakan 12 neuron pada lapisan input, 50 neuron pada lapisan tersembunyi, dan 1 neuron pada lapisan output.

Langkah selanjutnya adalah melakukan proses defuzzifikasi, yaitu proses pemetaan dari himpunan fuzzy kedalam himpunan crisp. Pada penelitian ini, defuzzifikasi merupakan tahap akhir untuk memperoreleh hasil peramalan. Adapun hasil peramalan penjualan sepeda motor untuk tahun 2019 menggunakan metode fuzzy neurol network dapat dilihat pada Tabel.4.

Table 4. Hasil Peramalan Penjualan Sepeda Motor tahun 2019

\begin{tabular}{cc}
\hline Bulan & $\begin{array}{c}\mathbf{2 0 1 9} \\
\text { (Unit) }\end{array}$ \\
\hline Jan & 153 \\
Feb & 133 \\
Mar & 114 \\
Apr & 116 \\
Mey & 125 \\
Jun & 157 \\
Jul & 120 \\
Aug & 114 \\
Sep & 122 \\
Okt & 125 \\
Nov & 160 \\
Dec & 115 \\
\hline
\end{tabular}




\section{SIMPULAN}

Fuzzy neural network yang digunakan dalam penelitian ini merupakan kombinasi logika fuzzy dengan pendekatan multilayer perceptron untuk peramalan penjualan sepeda motor. Konsep logika fuzzy digunakan untuk mengubah data crisp menjadi bilangan fuzzy, yang akan digunakan sebagai input pada jaringan syaraf. Arsitektur jaringan pada penelitian ini terdiri atas 12 neuron lapisan input, 50 neuron lapisan tersembunyi, dan 1 neuron pada lapisan output. Hasil peramalan penjualan sepeda motor untuk tahun 2019 adalah 153 unit pada bulan Januari, 133 unit pada bulan Februari, 114 unit pada bulan Maret, 116 unit pada bulan April, 125 unit pada bulan Mei, 157 pada unit pada bulan Juni, 120 unit pada Juli, 114 unit pada bulan Agustus, 122 unit pada bulan September, 125 unit pada bulan Oktober, 160 unit pada bulan November dan 115 unit pada bulan Desember.

Model jaringan ini memberikan nilai Means Square Error yang sangat kecil, yaitu sebesar 9.9924e-06 untuk data training dan 0.0560 untuk data testing. Oleh karena itu, dapat dikatakan bahwa dalam hal ini fuzzy neural network ini cocok digunakan untuk peramalan penjualan sepeda motor.

\section{DAFTAR PUSTAKA}

[1] S. Kusumadewi, "Artificial intelligence (teknik dan aplikasinya)," Yogyakarta Graha Ilmu, vol. 278, 2003.

[2] L. F. Mubin, W. Anggraeni, and A. Vinarti, "Prediksi Jumlah Kunjungan Pasien Rawat Jalan Menggunakan Metode Genetic Fuzzy Systems Studi Kasus: Rumah Sakit Usada Sidoarjo," J. Tek. ITS, vol. 1, no. 1, pp. A482-A487, 2012.

[3] A. Rahmadiani and W. Anggraeni, "Implementasi Fuzzy Neural Network untuk Memperkirakan Jumlah Kunjungan Pasien Poli Bedah di Rumah Sakit Onkologi Surabaya," J. Tek. ITS, vol. 1, no. 1, pp. A403-A407, 2012.

[4] B. G. A. Rizka and R. Kusumawati, "FUZZY FEED FORWARD NEURAL NETWORK UNTUK PERAMALAN INDEKS HARGA SAHAM GABUNGAN (IHSG) DENGAN ALGORITMA GENETIKA MENGGUNAKAN VARIASI SELEKSI," J. Mat., vol. 6, no. 3, pp. 1-9, 2017.

[5] M. R. P. Harahap and A. Suharsono, "Analisis Peramalan Penjualan Sepeda Motor di Kabupaten Ngawi dengan Arima dan Arimax," J. Sains dan Seni ITS, vol. 3, no. 2, pp. D122D127, 2014.

[6] Z. E. K. Tsani and D. E. Kusrini, "Peramalan Penjualan Sepeda Motor Baru Di Area Penjualan Surabaya Dengan Menggunakan Regresi Panel,” J. Sains dan Seni ITS, vol. 3, no. 2, pp. D158D163, 2014.

[7] F. Dristyan, "Prediksi Jumlah Penjualan Kredit Sepeda Motor Menggunakan Algoritma Backpropagation," in Seminar Nasional Royal (SENAR), 2018, vol. 1, no. 1, pp. 185-190.

[8] C.-T. Lin and C. S. G. Lee, Neural fuzzy systems: a neuro-fuzzy synergism to intelligent systems. Prentice hall, 1996.

[9] S. Kusumadewi and S. Hartati, "Neuro-Fuzzy: Integrasi Sistem Fuzzy dan Jaringan Syaraf," Yogyakarta Graha Ilmu, 2006. 